Portland State University

PDXScholar

University Honors Theses

University Honors College

$1-1-2012$

\title{
Defining CCL20's Role in Carcinogenesis
}

Melanie Schafer

Portland State University

Follow this and additional works at: https://pdxscholar.library.pdx.edu/honorstheses

Let us know how access to this document benefits you.

Recommended Citation

Schafer, Melanie, "Defining CCL20's Role in Carcinogenesis" (2012). University Honors Theses. Paper 5. https://doi.org/10.15760/honors.5

This Thesis is brought to you for free and open access. It has been accepted for inclusion in University Honors Theses by an authorized administrator of PDXScholar. Please contact us if we can make this document more accessible: pdxscholar@pdx.edu. 


\section{Defining CCL20's Role in Carcinogenesis}

By

Melanie Schafer

A thesis submitted in partial fulfillment of the requirements for the

HONORS RESEARCH PROGRAM

IN

BIOLOGY

Portland State University

2012 


\section{ACKNOWLEDGEMENTS}

I would like to acknowledge and extend my sincere appreciation to everyone in Dr. Molly Kulesz-Martin's Lab for their help, support and friendship. Without all these things this paper would not be possible. I want to thank Molly Kulesz-Martin for allowing me to come work in her lab and for all her direction and insight she offered throughout the completion of my project. I would also like to thank Yuangang Liu for guiding me through my project. He not only designed the experiments, but took the time to teach me numerous techniques and continued to assist me throughout the project, specifically in the mouse inoculation and tumor dissection as well as cell preparation. His supervision made this work possible. I would also like to acknowledge him for his assistance in writing my thesis. His willingness to answer all my questions and review my drafts was invaluable. I also want to thank Rebecca Bridges, who I worked with on the transfections of the cell line. Rebecca, along with Yun Wang and Jim Lagowski, helped me learn the layout of the lab and assisted me with troubleshooting. Jim also took a lot of time to teach me many different techniques and procedures for working with mice. I would also like to thank Zach Stupor for taking the time to cut all the slides for immunostaining and for his and Yun's advice in how to improve my staining technique.

I would also like to acknowledge my thesis committee: Michael Bartlett, Justin Courcelle, Molly Kulesz-Martin, and Jeffrey Singer. I am very appreciative of them for taking the time to review my paper and offer insight in to how to better it. 
TABLE OF CONTENTS

PAGE

ACKNOWLDEGEMENTS..........................................

LIST OF FIGURES AND GRAPHS.................................. 5

CHAPTERS

I. INTRODUCTION ......................................6

II. MATERIALS AND METHODS...........................11

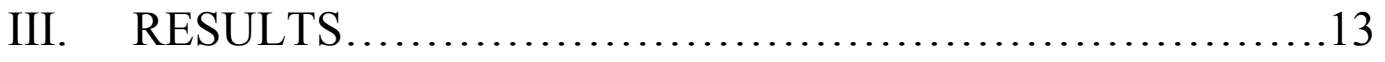

IV. DISCUSSION ......................................... 16

REFERENCES ......................................................20 
LIST OF FIGURES, GRAPHS AND CHARTS

\section{FIGURES}

1. Mechanism for CCL20 Inducible Cell Line.......................11

2. Measurement of Mass Size, Tumor Weight and Images of Head and Neck SCC stained for CCL20.............................15

3. Table of CCL20 Staining Intensity of Head and Neck SCC Accompanied with Representative Images of Intensities.......16

\section{GRAPHS}

1. Quantification of CCL20 Expression for Generated CCL20 Over Expressing Tumor Cell line...............................14 


\section{CHAPTER I \\ INTRODUCTION}

\section{Inflammation Background}

The inflammatory response plays a very important role in maintaining the overall state of the body and becomes activated when this state is disrupted by occurrence of tissue damage or presence of pathogens (reviewed in Murphy, 2007). Functions of inflammation include recruitment of effector cells to area of concern, release of chemicals that promote repair, and local changes in blood vessels that cause increase in permeability and size (reviewed in Murphy, 2007). These functions occur simultaneously and are also synergistic in nature, enhancing the function of one another to get the most optimal response (reviewed in Murphy, 2007). For example, the increase in both permeability and size of blood vessels acts to create a barrier that prevents the spread of the infection or damage (reviewed in Murphy, 2007). This change also allows

for more cells recruited by the inflammatory response to leave the circulatory system and enter the tissue (reviewed in Murphy, 2007).

When working correctly, the inflammatory response slowly shuts off after repairs have been completed due to expression of anti-inflammatory factors (Moustakas et al., 2002). However, if the expression of pro-inflammatory factors fails to subside, chronic inflammation can develop (reviewed in Coussens, 2002). Chronic inflammation has become widely accepted as having a casual relationship to cancer with an estimated 15$20 \%$ of all cancer deaths linked to inflammation (Balkwill et al, 2001; de Martel et al., 2009). Examples of inflammatory diseases associated with cancer include inflammatory bowel disease and colorectal cancer, bladder inflammation and bladder cancer, chronic pancreatitis and pancreatic cancer, and gingivitis and oral squamous cell carcinomas (Karin, 2006; Waldner et al, 2009; Wu et al., 2009).

\section{Inflammation and Cancer}

The relationship between chronic inflammation and cancer is dependent upon the microenvironment established by inflammation (Luo et al., 2004; Singh et al., 2009; Zhang et al., 2009). The microenvironment refers to the chemical factors and stroma 
present in an area with the stroma consisting of the extracellular matrix as well as fibroblasts, endothelial cells and immunocytes (Rollins, 2006). The microenvironment plays a pivotal role in the process of tumor initiation and promotion, both of which must occur in order for cancer to develop (reviewed in Coussens, 2002). In order for a tumor to arise, a normal cell must undergo some form of initiation that includes an alteration in the cell's DNA causing a change in its somatic state (Rous et al., 1941; Mackenzie et al., 1941).

Initiation can occur independent of inflammation but it can also be caused by it (reviewed in Coussens, 2002). The inflammatory response has the ability to alter cell's DNA by phagocytic cell's production of reactive oxygen species (ROS) and reactive nitrogen intermediates (RNI) that are used to fight against infection (Maeda et al., 1998). ROS and RNI react to form peroxynitrite, a powerful oxidant and mutagenic agent that causes DNA damage leading to the destruction of the infectious agent, but collateral damage can also occur to the body's cells (Maeda et al., 1998). Under normal conditions, a cell with significant DNA damage would undergo apoptosis, however, factors released by the inflammatory response include survival factors that prevent cell death (Lou et al., 2004). Survival factors are released on the premise that in order to maintain the function of the tissue in the context of a substantial number of cells being wounded, some cells must be kept regardless of their damage (Chen et al., 2003). Factors are not selective in the cells they affect and so they inadvertently prevent the apoptosis of the cells damaged by the peroxynitrite (Chen et al., 2003).

Initiation is not sufficient by itself to cause cancer and it must be followed by a promotion stage (reviewed in Coussens, 2002). Promotion involves repeated stimulation of tissue turnover that can be brought about by various stimuli but in the end results in the induction of cell proliferation (Grivennikov, 2010b). In the absence of proliferation, cells can exist with DNA damage indefinitely without becoming neoplastic (Grivennikov, 2010b). The inflammatory response establishes a microenvironment optimal for tumor progression by secreting factors supporting the tumor's growth and survival (Chang et al., 2004; Galon et al., 2006). Growth factors are released to enhance cell proliferation with the intention of regenerating the tissue that was injured, but can end up increasing the number of tumor cells (Singh et al., 2009; Mantovani et al, 2002). Along with inducing 
cell proliferation, many promotion events also function by recruiting inflammatory cells, reducing DNA damage repair mechanisms and preventing cell death all of which are involved in the inflammatory response and lead to a favorable state for neoplastic tissue development (Mantovani et al, 2002; Singh et al., 2009; Zhang et al., 2009). The inflammatory response produces such a supportive environment for cancer progression that it has been observed to be induced through oncogenes (Borrello et al., 2005). For instance in breast tumors, which have no previous underlying inflammation, an inflammatory microenvironment in the tumor is produced and this supports the importance of inflammation's role in cancer (Mantovani, 2008).

The factors secreted by the inflammatory response are small molecules known as cytokines that bind to receptors of cells affecting the behavior of that cell (reviewed in Coussens, 2002). Macrophages, the predominant phagocytic cell recruited by the inflammatory response, are attracted to the site of infection by concentration gradients established by cytokines (Moser et al., 2004). Upon arrival to the tissue and exposure to the infectious agent, macrophages become activated and begin secreting growth factors and cytokines (reviewed in Coussens, 2002). Released cytokines attract more macrophages that in turn become activated establishing a positive feedback loop that is self-limiting under normal conditions, but in chronic inflammation can become deregulated (Coussens et al., 2000; Lin et al., 2001; Mantovani et al., 1992)

\section{Chemokines in carcinogenesis}

A specific group of chemoattractant cytokines known as chemokines are responsible for stimulating migration of cells to a location as well as causing their activation (reviewed in Raman, 2007). Chemokines are a secreted type of cytokine that are relatively small and characterized by cysteine motifs in their amino acid sequence (Bacon et al., 2002). They can be categorized based upon their role in homeostasis and inflammation (Rossi, 2000). Chemokines classified as homeostatic are found in normal tissues when no inflammatory stimulus is present or are produced by cells that do not activate inflammation (Rossi, 2000). Inflammatory chemokines, as the name implies, are involved in the regulation of inflammation (Rossi, 2000). However, these two categories are not mutually exclusive 
since the functions of certain chemokines are different based on the cell and tissue type that they bind to (Rossi, 2000).

Chemokines have high specificity in the molecules they attract, but the same chemokine can also interact with a variety of receptors (Zlotnik et al., 2000). These receptors vary based upon cell type and the activation of certain cell types can depend more upon the pattern of chemokines expressed (Weber et al., 2006). The function of a chemokine depends upon the cell that the receptor it binds to is attached (reviewed in Raman et al., 2007). Along with stimulating motility, these functions include angiogenesis, wound healing, anti-apoptotic effects, proliferation, epithelial-mesenchymal transitions, pro and anti-tumor responses, and Th1/Th2 development (Arenberg et al., 1997; Bonecchi et al., 1998; Fernando et al., 2011; Zhang et al., 2012).

Chemokines have been found to be almost universally present in all cancers having context-dependent role (Muller et al, 2001; Mukaida et al., 2012; Rollins, 2006).

Initially, they can be beneficial attracting immunocytes, such as macrophages, that can destroy the tumor (Negus et al., 1997). However, the attraction of immunocytes later in tumor development can have detrimental consequences (Leek et al., 1996). Majority of cancerous cells secrete chemokines but they can also be released by stromal cells and can act in a mutual paracrine manner between the tumor and stromal cell (Mizuno, et al., 1994; Shih et al., 1994).

\section{Chemokine: T helper cell development}

Chemokines can also aid in the T cell polarization into Th1 or Th2 (Bonecchi et al., 1998). Th1 and Th2 are both subsets of $\mathrm{CD}^{+} \mathrm{T}$ helper cells, but have different functions (Mosmann et al., 1986; Sallusto et al., 1998). Th1 has anti-tumor functions activating macrophages, managing the production of certain cytotoxic $\mathrm{T}$ cells and secreting cytokines including the interferon IFN- $\gamma$ (activates macrophages) and the interleukin IL2 (attracts white blood cells) (Cherwinski et al., 1987; Li et al., 1993; Mosmann et al., 1986). Th2 opposes the anti-tumor functions of Th1 by decreasing the activity of cytotoxic T cells (Cunha et al., 1992; Sallusto et al., 1998; Viola et al., 2006). It also secretes IL-4 (causes differentiation of naive helper $t$ cells to Th2), IL-5 (induces B-cell growth and secretion), IL-10 (immunosuppressive) and IL-13 (anti-inflammatory and 
differentiation functions) (Mosmann et al., 1986; Swain et al., 1988). Th2 can also induce macrophages into M2 macrophages that enhance expression of IL-10 further enhancing tumor growth and development (Mantovani et al., 2002).

Another subset of $\mathrm{T}$ helper cell that is affected by chemokines is Th17, named because it secretes IL-17 (Park et al., 2005). Its production of this cytokine along with others has classified it as having pro-inflammatory functions (Fossiez et al., 1996). One of Th17's known functions is fighting extracellular infections and it is does this through cytokines it releases (Aujla et al., 2007). These cytokines lead to the production of antimicrobial peptides and recruitment of immunocytes (Liang et al., 2006; Liang et al., 2007). CCR6 is one of Th17's principal receptors and is a specific marker for Th17 (Liao et al., 1999; Singh et al., 2008). CCR6 is also present on a variety of other leukocytes, including dendritic cells, T cells, B cells, neutrophils and Tregs (Baba et al., 1997; Greaves et al., 1997; Yamashiro et al., 2000). It is also unique in that it only interacts with one specific chemokine called CCL20 (Greaves et al., 1997).

CCL20 is expressed by a variety of cells including macrophages, dendritic cells, B cells, T cells, and eosinophils (Hromas et al., 1997; Kleeff et al., 1999; Sullivan et al., 1999). Many of the cells that secrete CCL20 also express CCR6 on their surface enabling CCL20 to act in an autocrine manner in conjunction with its ability to function as a paracrine agent (Kleeff et al., 1999). CCL20 is found in a variety of normal tissues such as colon, pancreas, prostate, uterine cervix and skin classifying it as a homeostatic chemokine (Cremel et al., 2006; Ghadjar et al., 2008; Kleeff et al.,1999; Varona et al., 1998). It is also considered to be an inflammatory chemokine because it's expression can be induced in keratinocytes by proinflammatory cytokines TNF- $\alpha$ and/or IL-1 $\beta$ (Chabaud et al., 2001; Fujiie et al., 2001; Nakayama et al., 2001). CCL20's role in inflammation includes binding to the cell surface receptor CCR6 on leukocytes causing them to migrate (Greaves et al., 1997; Krzysiek et al., 2000; Liao et al., 1999; Varona et al., 2001).

It has previously been hypothesized that if tumor cells express both CCR6 and CCL20 then CCL20 might affect tumor development positively through autocrine and paracrine mechanisms (Kleeff et al., 1999; Ghadjar et al., 2009). CCL20 secreted by tumor cells could bind to CCR6 expressed on these same cells increasing their growth (Kleeff et al., 
1999; Ghadjar et al., 2009). Conversely, CCL20 can interact with the stroma surrounding tumor cells creating a more suitable microenvironment for the tumor (Kleeff et al., 1999; Ghadjar et al., 2009). Due to CCL20 ability to stimulate migration in leukocytes, it is also possible that it could aid in the metastasis of tumor cells (Greaves et al., 1997; Ghadjar et al., 2009; Krzysiek et al., 2000; Liao et al., 1999; Varona et al., 2001). In a study conducted by Ghadjar et al. on colorectal cancer patients, it was discovered that CCR6 expression on tumor cells increased the risk of liver metastasis (Ghadjar et al., 2006). Furthermore, Rubie et al. demonstrated that CCL20 levels were higher in patients with colorectal cancer that had metastasized to the liver (Rubie, 2006). These studies support the hypothesis that CCL20 has a role in cancer development. The aim of this study is to define CCL20's impact on cancer, and since CCL20 is a Th17 specific chemokine, it will allow us to shed light onto Th17's role in cancer. Although the contribution of Th1 and Th2 in carcinogenesis has been well established, Th17's function in cancer development has yet to be identified.

\section{CHAPTER II}

\section{MATERIALS AND METHODS}

Establishing CCL20 expressing tumor cells: An 03R cell line derived from normal $\mathrm{balb} / \mathrm{c}$ mice keratinocytes that had undergone initiation forming a squamous cell carcinoma derivative was used to generate a CCL20 inducible cell line (Han et al., 1992; Kulesz-Martin et al., 1986; Kulesz-Martin et al., 1988). The 03R cell line was transfected with a CCL20 plasmid. The plasmid contained CMV, a general promoter for CCL20, tetracycline repressor element (TRE), which is a DNA element for tetracycline repressor to bind to, and tetracycline repressor (TR), which binds to TRE when tetracycline is absent (see figure 1). ELISA was used to measure the CCL20 expression levels of clones generated. 


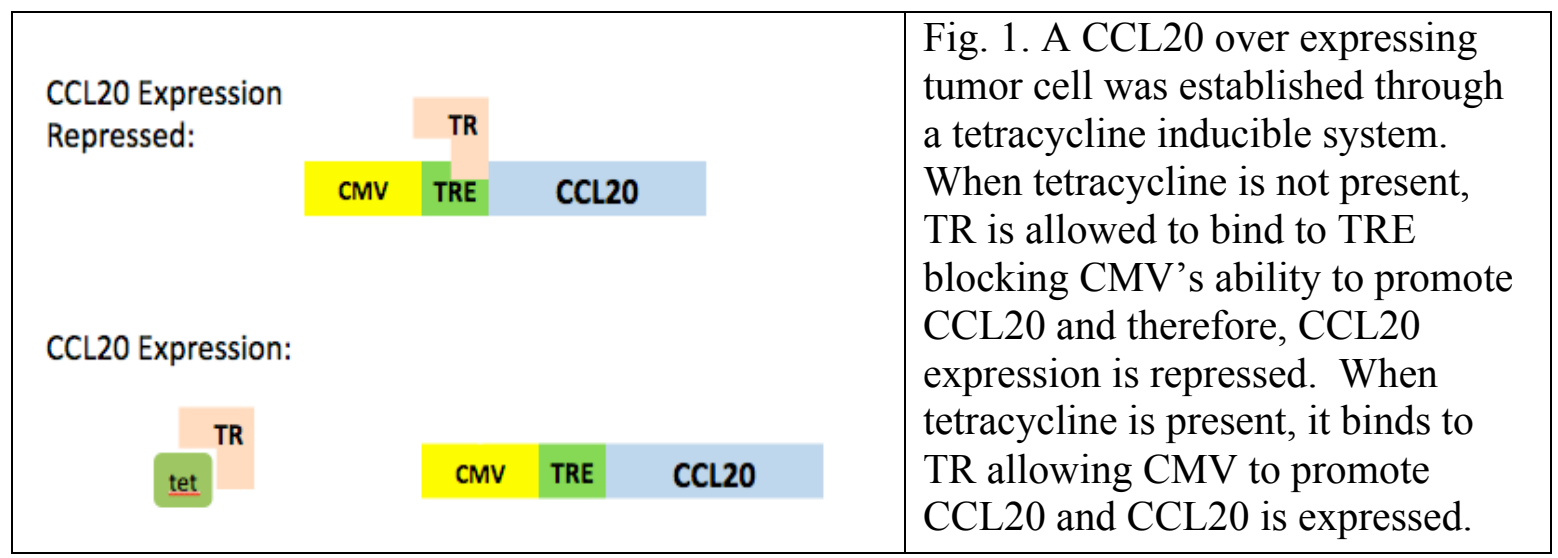

Analysis of CCL20 expression of transfected tumor cells by ELISA: Tetracycline medium was collected from each clone and frozen. Then . $1 \mu \mathrm{L}$ of tetracycline was added to the medium of each clone and allowed to sit overnight. The following morning, the medium was collected. CCL20 levels were of the medium with tetracycline and the medium without it were measured using an ELISA from R\&D systems. Results are expressed as picograms per milograms.

Evaluating tumorigenicity of CCL20 expressing tumor cells in vivo: Balb/c mice were housed in Oregon Health and Science University's Barrier under pathogen free conditions and the animal study was performed in accordance to Oregon Health and Science University’s Institutional Animal Care \& Use Committee (IACUC). A 1:1 mixture of $0.1 \mathrm{~mL}$ solution of CCL20 expressing tumor cells and 03R parental cell line were injected subcutaneously into the backs of neonates. CCL20 expression was induced by tetracycline treatments that were administered in 5\% sucrose water at a concentration of $0.3 \%$ tetracycline.

The tumors on the mice were measured twice a week and the size was calculated by the formula: tumor length $\mathrm{x}$ tumor width. Tumor size was measured until it reached a size of approximately $2 \times 2 \mathrm{~cm}$ upon which they mice were terminated under the protocol approved by OHSU's IACUC. Upon termination, the tumor was removed and placed in a formaldehyde solution for one day and then replaced with $70 \%$ ethanol. The tumors were then sent to OHSU's core were each tumor was sectioned and stained with H\&E. 
Evaluating CCL20 expression in human HNSCC: ABC staining was performed on 20 head and neck squamous carcinoma samples along with normal uninvolved human skin to act as a negative control and psoriatic skin (Liu et. al., 2010) to use as a positive control. Of the 20 samples, 8 were tumor samples without positive nodes, six had positive nodes, and the remaining six had metastasized. In order to prevent non-specific binding, the slides were incubated in PAP (PBS, $0.05 \%$ sodium azide, $2 \%$ BSA) for one hour. The slides were then incubated overnight at $4^{\circ} \mathrm{C}$ with a goat primary antibody. The secondary antibody used was a CCL20 anti-goat (G-20) manufactured by Santa Cruz. The $\mathrm{ABC}$ staining was done using a Vectastain $\mathrm{ABC}$ kit from vector labs and the slides were then counterstained with hematoxylin.

\section{CHAPTER III}

\section{RESULTS}

\section{Generation of Tetracycline inducible CCL20 tumor cell lines}

In order to evaluate CCL20's affects on tumorigenesis, we generated a cell line that could be induced to over express CCL20 using a tetracycline inducible system. A tumorigenic cell line (03R) was chosen as the line to transfect due to its similarity to SCCs. We selected 48 stable cell clones to test CCL20 inducibility by tetracycline. The CCL20 expression was measured by CCL20 ELISA. The clones with more than 10 fold CCL20 induction upon tetracycline treatment were selected (Figure 2A). A total of 3 clones were found to over express CCL20: clones 1, 11, and 14, with clone 11 being induced to express CCL20 approximately 30 times more than without induction (figure 1A). The highest CCL2 2 expression $(900 \mathrm{pg} / \mathrm{ml})$ is within the range of CCL2 0 expression in normal keratinocytes (291) treated with TNFa (Figure 2B). 


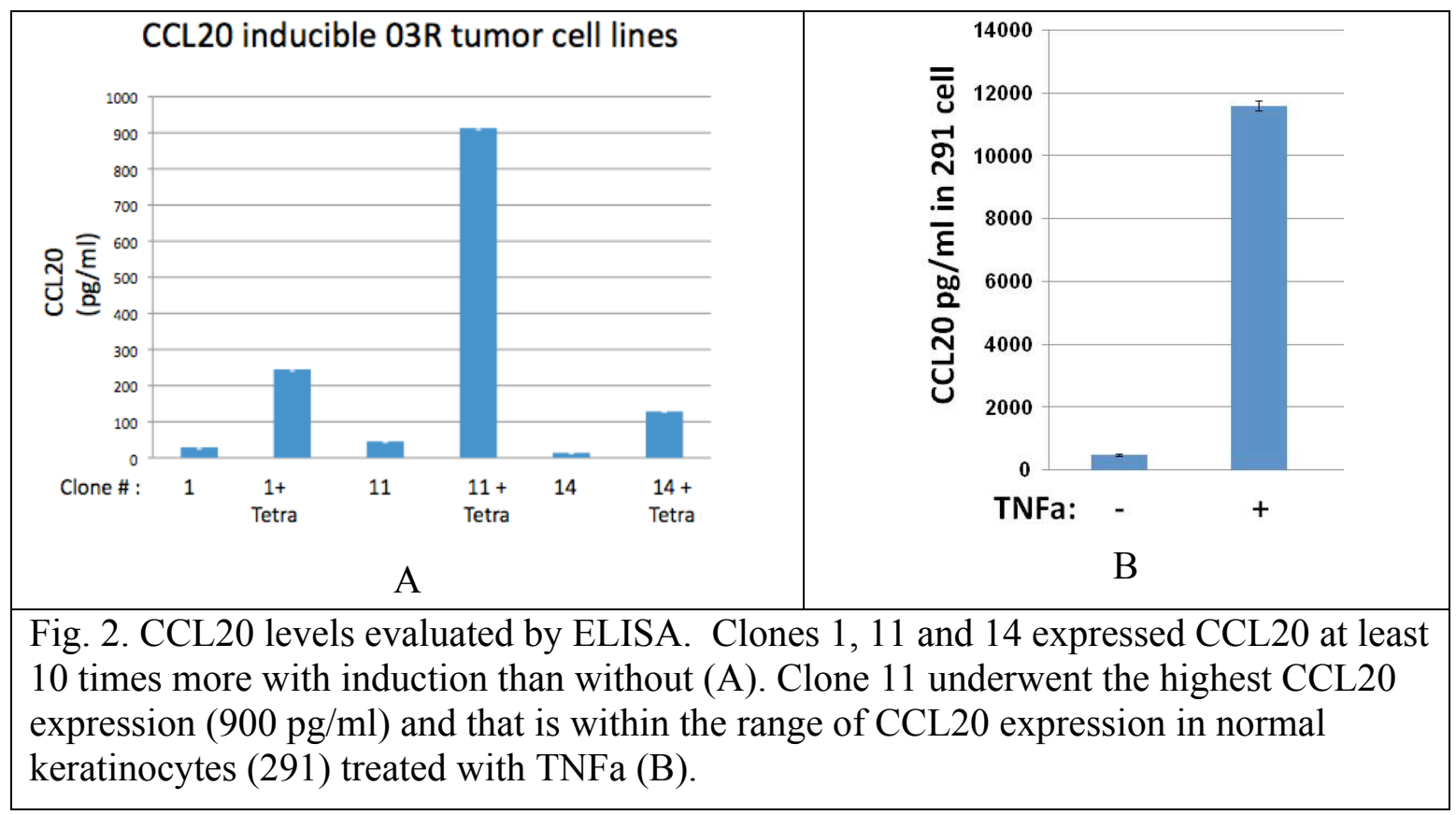

\section{Evaluation of 03R tumorigenesis in response to CCL20 expression}

We explored CCL20's role in tumor development in vivo by inoculating BALB/c neonates subcutaneously with a 1:1 mixture of clone 11 and the $03 \mathrm{R}$ parental cell line ( $\mathrm{xxx}$ cells total). 03R parental cell line was used to inoculate the mice in case clone 11 had undergone a loss in tumorigenicity after undergoing transfection. The mice were split into two groups with one receiving tetracycline treatments starting at three weeks after inoculation and masses that developed were measured. Mice that were inoculated with the mixture of parental 03R cell line and clone 11 along with tetracycline treatments developed larger masses, as seen in Figure 3A. However, because of the development of hematocysts which compromised assessment of tumor development, the weight of the tumors for each group were measured after the masses were dissected. Figure 3B shows that the group of mice treated with tetracycline followed a general trend of having larger masses than the group that did not receive tetracycline treatment.

Although there was a tendency of increased size of masses at the injection sites, the tumor weights from 03R/CCL20 with or without tetracycline was not statistically significant by 2 tailed Student $t$ test. The trend of increased tumor growth upon CCL20 expression suggests that CCL20 has a possible role in aiding tumor development. Further study with increased number of mice is needed to define the role of CCL20 in carcinogenesis. 


\begin{tabular}{l}
\hline \multicolumn{3}{|c|}{ Mass Size } \\
\hline
\end{tabular}

The tumors collected from the mice were stained with H\&E to see if there was any histological difference between the mice receiving tetracycline treatments and those that did not (Figure 3C). The tumors of the mice given tetracycline treatments appear to have more infiltration of immunocytes into the tumor cells than the tetracycline negative mice whose immunocyte cells are slightly more separated from the tumor cells. However, there is no significant correlation between the infiltration of immunocytes versus tumor growth. Apparent differences were small, indicating that CCL20 effects on tumor growth, if any, may require more samples in order to establish a correlation.

\section{Evaluation of CCL20 expression in human head and neck carcinoma}

CCL20 expression was evaluated in head and neck SCCs. Three different groups of SCC were used: one group without positive nodes, a second group with positive nodes, and a final group of samples that had metastasized (staining results summarized in Figure 4). 


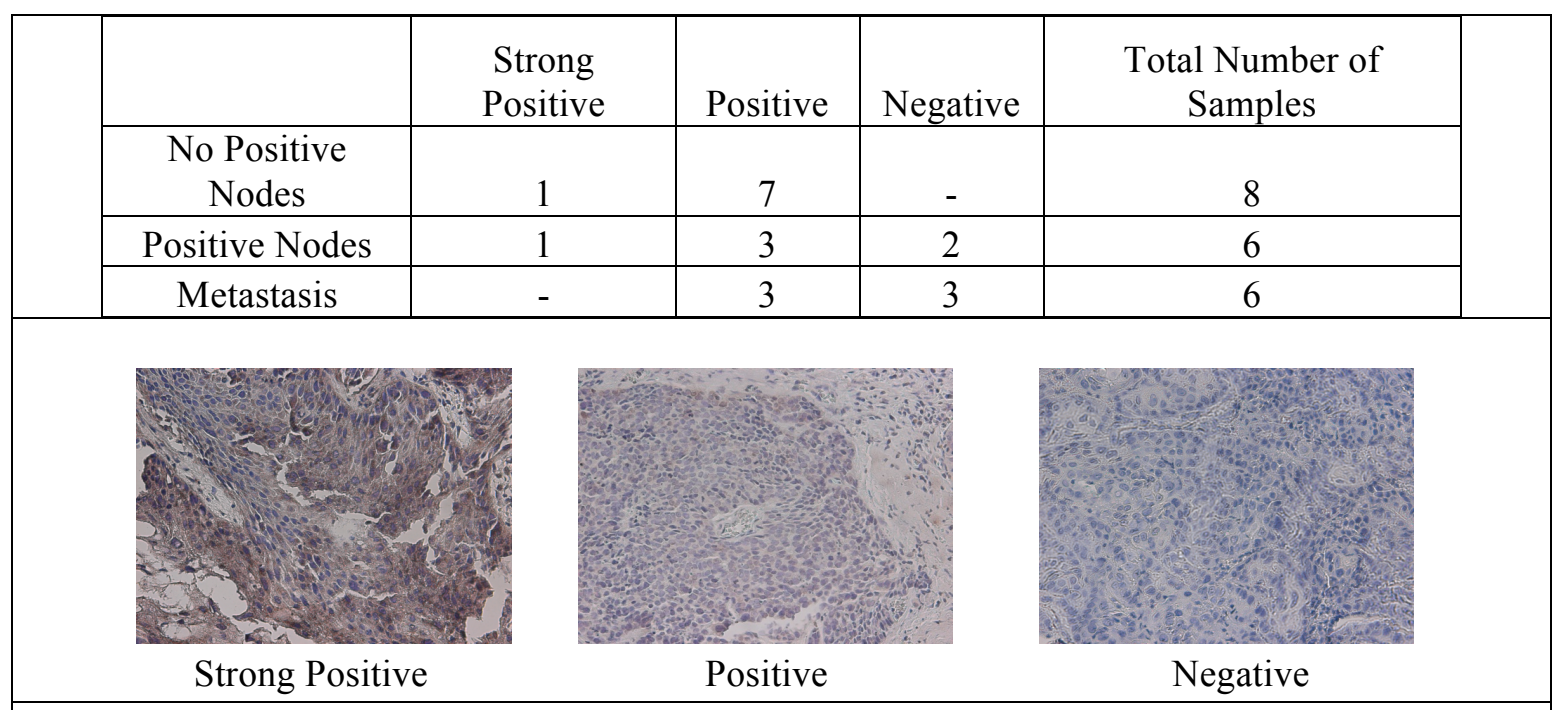

Fig. 4. CCL20 staining intensity in human HNSCC. Top panel is the summary of immunostaining results. Tumor samples without positive nodes all stained positive for CCL20 while more variation of CCL20 staining was seen in tumor samples with positive nodes and tumor samples that had metastasized. The lower panel contains representative staining images of HNSCC samples stained with CCL20.

All of the tumor samples from the group with no positive nodes stained positive for CCL20 with one of them staining very strongly. Samples from the groups with positive nodes and those that had metastasized, showed more variability in CCL20 expression. Half of the samples with positive nodes stained positive for CCL20. Of the remaining half, one stained strongly positive and two were negative. Of the tumor samples that had metastasized, half stained positive and the other half of the samples were negative. Staining of CCL20 shows that its expression is present throughout cancer progression including in the earliest stages tested, since all tumors without positive nodes stained positive for it.

\section{CHAPTER IV}

\section{DISCUSSION}

In this study, we provided experimental evidence regarding association of CCL20 with tumorigenesis. Examining CCL20 in the context of SCC, we found that when CCL20 was over expressed, tumor size tended to increase; however this did not reach statistical significance. Enhanced tumor size could be attributed to a number of possible functions 
related to CCL20. It has been established that CCL20 acts as a chemoattractant recruiting immunocytes to areas that exhibit high concentrations of CCL20 (Ghadjar et al., 2009). The increase in tumor size could be explained by an increase in immunocytes that were recruited to the tumor by CCL20. Due to cancer's ability to hijack the inflammatory response and use it for its advantage, the immunocytes may be acting to aid in tumor cell progression or it is possible they are functioning to fight the tumor cells. Several limitations of our study leave CCL20's and Th17's functional roles unidentified and a clear relationship between CCL20 and cancer has yet to be established. Specifically, long-term studies are needed in order to evaluate the influence CCL20 on tumorigenesis.

When the histology of the tumors from the in vivo study were examined, it appeared that mice treated with tetracycline had increased infiltration of immunocytes in tumors compared to mice that did not receive treatment. However, there were no significant correlations between the infiltration of immunocytes versus tumor growth in the small sample sizes of our study. Furthermore, we do not know what types of immunocytes infiltrated tumor tissue. It has been established that CCL20 recruits Th17, Treg, and B cells, making it rational to conclude that these are the immunocytes present in samples in which CCL20 was over-expressed (Greaves et al., 1997; Krzysiek et al., 2000; Liao et al., 1999; Varona et al., 2001). However, the function of these immunocytes has yet to be defined, because, as stated above, they could be aiding in tumor development or impeding it.

In addition, a limitation of this in vivo study was the unexpected development of hematocysts that interfered with the measurement of tumors. The study was initially designed to last for a longer period of time in order for us to observe CCL20's more extended effect on tumor growth and in addition, tumor metastasis. The study was significantly shorter than what is necessary to observe metastasis. There are a few possible causes for the development of hematocysts, including the invasiveness of the 03R tumor cell line used to inoculate the mice. A previous pilot study we conducted inferred that clone \#11 had undergone a loss in tumorigenicity after undergoing transfection. This is why in the following experiments we used a mixture of parental $03 \mathrm{R}$, which was expected to produce tumors in $\sim 100 \%$ of injection sites, with clone 11 , to 
provide a source of CCL20 in the tumor environment, to inject the mice. However, 03R's ability to generate tumors may be have already been maximal, minimizing the impact of CCL20, or the manipulation of cells required for our experiment may have stimulated production of the hematocysts. A possible solution for this problem could be simply increase the $03 \mathrm{R}$ cell ratio in the mixture used to inject the mice. An optimization study that utilized varying dilutions would need to be conducted in order to determine the appropriate concentration.

Furthermore, although significant CCL20 induction was achieved in 03R clone \#11 (more than 10 fold induction), the CCL20 induction level was far less than the CCL20 level produced from normal keratinocytes in culture treated with TNF $\alpha$ (see Figure $2 b$ in results section). Future tumorigenesis studies with higher CCL20 induction (equivalent to that in stimulated normal keratinocytes) in the $03 \mathrm{R}$ tumor cell are needed to define the pathological role CCL20 in tumorigenesis.

Staining of CCL20 in human head and neck SCC samples showed that CCL20 expression is present throughout cancer progression including in the early stages prior to lymph node involvement. This is consistent with the initial reports from our laboratory showing Trim32, a positive regulator of NFkB and CCL20, at the initiation stages of carcinogenesis (Horn et al., 2004). While staining of CCL20 in the SCC samples establishes the presence of CCL20 it does not define its role. Even so, when taken in conjunction with the current in vivo study, it is possible to infer that CCL20's presence throughout cancer progression may act to increase tumor size. CCL20 expression was found to be consistently present on tumors without positive nodes, which represent tumors in the beginning stages of cancer. Therefore, its expression could contribute to the microenvironment of the tumor in such a way that is supportive of the tumor progression.

Further studies are needed in order to establish a relationship between cancer and CCL20. If a relationship is found, it could be used to generate new therapy techniques in the treatment of certain types of cancer. For example, if a positive relationship is established, treatments could be created to inhibit CCL20 expression or to target CCL20's ability to act as a ligand to CCR6. In contrast, if a negative association is discovered, treatments 
could focus on increasing CCL20 expression in hopes of hindering cancer development. By further defining CCL20's function in cancer, it will ultimately help us to characterize the role of Th17 cells in cancer. 


\section{REFERENCES}

Aujla, S.J., et al., Th17 cells and mucosal host defense. Seminars in Immunology, 2007. 19(6): p. 377-82.

Arenberg, D.A., et al., The role of $C X C$ chemokines in the regulation of angiogenesis in non-small cell lung cancer. Journal of Leukocyte Biology, 1997. 62(5): p. 554-62.

Baba, M., et al., Identification of CCR6, the specific receptor for a novel lymphocytedirected CC chemokine LARC. Journal of Biological chemistry, 1997. 272(23): p. 14893-8.

Bacon, K., et al., Chemokine/chemokine receptor nomenclature. Journal of Interferon and Cytokine Research, 2002. 22(10): p. 1067-8.

Balkwill, F., et al., Inflammation and cancer: back to Virchow?. Lancet, 2001. 357(9255): p. 539-45.

Balkwill, F., Chemokine biology in cancer. Seminars in Immunology, 2003. 15(1): p. 4955.

Bonecchi, R., et al., Divergent effects of interleukin-4 and interferon-gamma on macrophage-derived chemokine production: an amplifcation circuit of polarized Thelper 2 responses. Blood, 1998. 92(8): p. 2668-71.

Borrello, M.G., et al., Induction of a proinflammatory program in normal human thyrocytes by the RET/PTC1 oncogene. Proceedings of the National Academy of Sciences of the United States of America, 2005. 102(41): p. 14824-30.

Chabaud, M., et al., Enhancing effect of IL-1, IL-17, and TNF-alpha on macrophage inflammatory protein-3aplha production in rheumatoid arthritis: regulation by soluble receptors and Th2 cytokines. Journal of Immunology, 2001. 167(10): p. 6015-20.

Chang, H., et al., Gene expression signature of fibroblast serum response predicts human cancer progression: similarities between tumors and wounds. PLoS Biology, 2004. 2(2): e7. 
Chen, L., et al., The two faces of IKK and NK-kappaB inhibition: prevention and of systemic inflammation but increased local injury following intestinal ischemiareperfusion. Nature Medicine, 2003. 9(5): p. 575-81.

Cherwinski, H.M., et al., Two types of mouse helper T cell clone. III. Further differences in lymphokine synthesis between Th1 and Th2 clones revealed by RNA hybridization, functionally monospecific bioassays, and monoclonal antibodies. Journal of Experimental Medicine, 1987. 166(5): p. 1229-44.

Cornerford, I., et al., An Immune Paradox: How can the same chemokine axis regualte both immune tolerance and activation?. Bioessays, 2010. 32(12): p. 1067-76

Coussens, L.M., et al., MMP-9 supplied by bone marrow-derived cells contributes to skin carcinogenesis. Cell, 2000. 103(3): p. 481-90.

Coussens, L., et al., Inflammation and cancer. Nature, 2002. 420(6917): p. 860-7.

Cremel, M., et al., Female genital tract immunization: evaluation of candidate immunoadjuvants on epithelial cell secretion of CCL2O and dendritic/Langerhans cell maturation. Vaccine, 2006. 24(29-30): p. 5744-54.

Cunha, F.Q., et al., Interleukin-10 (IL-10) inhibits the induction of nitric oxide synthase by interferon-gamma in murine macrophages. Biochemical and Biophysical Research Communications, 1992. 182(3): 1155-9.

de Martel, C., et al. Infections and cancer: established associations and new hypotheses. Critical Reviews in Oncology/Hematology, 2009. 70(3): p. 183-94.

Fernando, R.I., et al., IL-8 signaling plays a critical role in the epithelial-mesenchymal transition of human carcinoma cells. Cancer Research, 2011. 71(15): p. 5296306.

Fossiez, F., et al., T cell interleukin-17 induces stromal cells to produce proinflammatory and hematopoietic cytokines. Journal of Experimental Medicine, 1996. 183(6): p. 2593-603.

Fujiie, S., et al., Proinflammatory cytokines induce liver and activation-regulated chemokine/macrophage inflammatory protein-3alpha/CCL20 in mucosal 
epithelial cells through NF-kappaB. International Immunology, 2001. 13(10): p. 1255-63.

Galon, J., et al., Type, density, and location of immune cells within human colorectal tumors predict clinical outcome. Science, 2006. 313(5795): p. 1960-4.

Ghadjar, P., et al., Chemokine receptor CCR6 expression level and liver metastasis in colorectal cancer. Journal of Clinical Oncology, 2006. 24(12): p. 1910-16.

Ghadjar, P., et al. Chemokine receptor CCR6 expression level and aggressiveness of prostate cancer. Journal of Cancer Research and Clinical Oncology, 2008. 134(11): p. 1181-9.

Ghadjar, P., et al., The chemokine CCL20 and its receptor CCR6 in human malignancy with focus on colorectal cancer. International Journal of Cancer, 2009. 125(4): p. 741-5.

Greaves, D.R., et al., CCR6, a CC chemokine receptor that interacts with macrophage inflammatory protein 3aplha and is highly expressed in human dendritic cells. Journal of Experimental Medicine, 1997. 186(6): p. 837-44.

Grivennikov, S.I., et al., Immunity, Inflammation and Cancer. Cell, 2010. 140(6): p. 88399.

Grivennikov, S.I., et al., Inflammation and oncogenesis: a vicious connection. Current Opinion in Genetics \& Development, 2010. 20(1): p. 65-71.

Han, K.A., et al., Altered expression of wild-type p53 tumor suppressor gene during murine epithelial cell transformation. Cancer Research, 1992. 52(3): p. 749-53.

Horn, E.J., et al., Ring protein Trim32 associated with skin carcinogenesis has antiapoptotic and E3-ubiquitin ligase properties. Carcinogenesis, 2004. 25(2): p. 15767.

Hromas, R., et al., Cloning and characterization of exodus, a novel beta-chemokine. Blood, 1997. 89(9): p. 3315-22.

Karin, M., Nuclear factor-kappaB in cancer development and progression. Nature 2006. 441(7092): p. 431-36. 
Kleeff, J., et al., Detection and localization of Mip-3alpha/LARC/Exodus, a macrophage proinflammatory chemokine and its CCR6 receptor in human pancreatic cancer. International Journal of Cancer, 1999. 81(4): p. 650-7.

Krzygeik, R., et al., Regulation of CCR6 chemokine receptor expression and responsiveness to macrophage inflammatory protein-3alpha/CCL20 in human B cells. Blood, 2000. 96(7): p. 2338-45.

Kulesz-Martin, et al., Benign and malignant tumor stages in a mouse keratinocyte line treated with 7, 12-dimethylbenz(a)anthracene in vitro. Carcinogenesis, 1988. 9(1): p. 171-4.

Kulesz-Martin, et al., Retinoic acid enhancement of an early step in transformation of mouse epidermal cells in vitro. Carcinogenesis, 1986. 7(9): p. 1425-9.

Leek, R.D., et al., Association of macrophage infiltration with anigogenesis and prognosis in invasive breast carcinoma. Cancer Research, 1996. 56(20): p. 46259.

Li, X.F., et al., Transforming growth factor-beta (TGF-beta)-mediated immunosuppression in tumor-bearing state: enhanced production of TGF-beta and a progressive increase in TGF-beta susceptibility of anti-tumor CD4+ T cell function. Japanese Journal of Cancer Research, 1993. 84(3): p. 315-25.

Liang, S.C., et al., Interleukin (IL)-22 and IL-17 are coexpressed by Th17cells and cooperatively enhance expression of antimicrobial peptides. Journal of Experimental Medicine, 2006. 203(10): p. 2271-9.

Liang, S.C. et al., An IL-17F/A heterodimer protein is produced by mouse Th17 cells and induces airway neutrophils recruitment. Journal of Immunology, 2007. 179(11): p. 7791-9.

Liao, F., et al., CC-chemokine receptor 6 is expressed on diverse memory subsets of $T$ cells and determines responsiveness to macrophage inflammatory protein 3 alpha. Journal of Immunology, 1999. 162(1): p. 186-94.

Lin, E.Y., et al., Colony-stimulating factor 1 promotes progression of mammary tumors to malignancy. Journal of Experimental Medicine, 2001. 193(6): p. 727-40. 
Liu, Y., et al., Regulation of the Psoriatic Chemokine CCL20 by E3 ligases Trim32 and Piasy in Keratinocytes. Journal of Investigative Dermatology, 2010. 130(5): p. 1384-90.

Luo, JL., et al., Inhibition of NF-kappaB in cancer cells converts inflammation-induced tumor growth mediated by TNFalpha to TRAIL-mediated tumor regression. Cancer Cell, 2004. 6(3): p. 297-305.

Mackenzie, I., et al., The experimental disclosure of latent neoplastic changes in tarred skin. The Journal of Experimental Medicine, 1941. 73(3): p. 391-416.

Maeda, H., et al., Nitric oxide and oxygen radicals in infection, inflammation and cancer. Biochemistry, 1998. 63(7): p. 854-56.

Mantovani, A., et al., The origin and function of tumor-associated macrophages. Immunology Today, 1992. 13(7): p. 265-70.

Mantovani, A., et al., Macrophage polarization: tumor-associated macrophages as a paradigm for polarized M2 mononuclear phagocytes. Trends in Immunology, 2002. 23(11): p. 549-55.

Mantovani, A., et al., Cancer-related inflammation. Nature, 2008. 454(7203): p. 436-44

Mantovani, A., Molecular Pathways Linking Inflammation and Cancer. Current Molecular Medicine, 2010. 10(4): p. 369-73.

Mizuno, K., et al., Autonomous expression of cytokine genes by human lung cancer cells and their paracrine regulation. Japanese Journal of Cancer Research, 1994. 85(2): p. 179-86.

Moser, B., et al., Chemokines: multiple levels of leukocyte migration. Trends in Immunology, 2004. 25(2): p. 75-84.

Mosmann, T.R., et al., Two types of murine helper T cell clone. I. Definition according to profiles of lymphokine activities and secreted proteins. Journal of Immunology, 1986. 136(7): p. 2348-57.

Moustakas, A., et al., Mechanisms of TGF-beta signaling in regulation of cell growth and differentiation. Immunology Letters, 2002. 82(1-2): p: 85-91. 
Mukaida, N., et al., Chemokines in tumor development and progression. Experimental Cell Research, 2010. 318(2): p. 95-102.

Muller, A., et al., Involvement of Chemokine receptors in breast cancer metastasis. Nature, 2001. 410(6824): p. 50-56.

Murphy, K. Janeway's Immunobiology. $8^{\text {th }}$ Edition. New York: Garland Science, 2007.

Nakayama, T., et al., Inducible expression of a CC chemokine liver-and activationregulated chemokine (LARC)/macrophage inflammatory protein (MIP)-3 alpha/CCL20 by epidermal keratinocytes and its role in atopic dermatitis. International Journal of Immunology, 2001. 13(1): 95-103.

Negus, R.P.M., et al., A quantitative assessment of the leukocyte infiltrate in ovarian cancer and its relationship to the expression of $C$ - $C$ chemokines. The American Journal of Pathology, 1997. 150(5): p. 1723-34.

Park, H., et al., A distinct lineage of CD4 T cells regulates tissue inflammation by producing interleukin 17. Nature Immunology, 2005. 6(11): p. 1133-41.

Rakoff-Nahoum, S., Why cancer and inflammation?. Yale Journal of Biology and Medicine, 2006. 79(3-4): p. 123-30.

Raman, D., et al., Role of Chemokines in tumor growth. Cancer Letters, 2007. 256(2): p 137-65.

Rollins, B., Inflammatory chemokines in cancer growth and progression. European Journal of Cancer, 2006. 42(6): p 760-67.

Rossi, D., et al., The biology of chemokines and their receptors. Annual Review of Immunology, 2000. 18(1): p. 217-42.

Rous, P., et al., Conditonal neoplasms and subthreshold neoplastic states: a study of the tar tumors of rabbits. The Journal of Experimental Medicine, 1941. 73(3): p. 365-90.

Rubie, C., Involvement of chemokine receptor CCR6 in colorectal cancer metastasis. Tumor Biology, 2006. 27(3): p. 166-74. 
Sallusto, F., et al., Chemokines and chemokine receptors in T-cell priming and Th1/Th2 mediated responses. Immunology Today, 1998. 19(12): p. 568-74.

Shih, I.M., et al., Autocrine and paracrine roles for growth factors in melanoma. In Vivo, 1994. 8(1): p. 113-23.

Singh, S.P., et al., Human T cells that are able to produce IL-17 express the chemokine receptor CCR6. Journal of Immunology, 2008. 180(1): p: 214-21.

Singh, S., et al., CXCR1 and CXCR2 enhances human melanoma tumorigenesis, growth and invasion. British Journal of Cancer, 2009. 100(10): p. 1638-46.

Sullivan, S.K., et al., MIP-3alpha induces human eosinophil migration and activation of the mitogen-activate protein kinases (p42/p44 MAPK). Journal of Leukocyte Biology, 1999. 66(4): p. 674-82.

Swain, S.L., et al., The role of IL4 and IL5: characterization of a distinct helper T cell subset that makes IL4 and IL5 (Th2) and requires priming before induction of lymphokine secretion. Immunology Review, 1998. 102: p. 77-105.

Varona, R., et al., Molecular cloning, functional characterization and mRNA expression analysis of the murine chemokine receptor CCR6 and its specific ligand MIP3alpha. FEBS Letter, 1998. 440(1-2): p. 188-94.

Varona, R., et al., CCR6-deficient mice have impaired leukocyte homeostasis and altered contact hypersensitivity and delayed-type hypersensitivity responses. Journal of Clinical Investigation, 2001. 107(6): R37-45.

Waldner, M.J., et al., Colitis-associated cancer: the role of T cells in tumor development. Seminars in Immunopathology, 2009. 31(2): p. 249-56.

Weber, C., et al., Fine-tuning leukocyte responses: towards a chemokine 'interactome'. Trends in Immunology, 2006. 27(6): 268-73.

$\mathrm{Wu}, \mathrm{S}$, , et al., A human colonic commensal promotes colon tumorigenesis via activation of T helper type 17 T cell responses. Natural Medicine, 2009. 15(9): p: 1016-22.

Yamashiro, S., et al., Expression of CCR6 and CD83 by cytokine-activated human neutrophils. Blood, 2000. 96(12): p. 3958-63. 
Zhang, X.H, et al., Latent bone metastasis in breast cancer tied to Src-depedent survival signals. Cancer Cell, 2009. 16(1): p. 67-78.

Zhang, Y., et al., SDF-1/CXCR4 axis in myelodysplastic syndromes: correlation with angiogenesis and apoptosis. Leukemia Research, 2012. 36(3): p. 281-6.

Zlotnik, A., et al., Chemokines: a new classification system and their role in immunity. Immunity, 2000. 12(2): p. 121-7. 